Article

\title{
Spatiotemporal Variability of Carbon Flux from Different Land Use and Land Cover Changes: A Case Study in Hubei Province, China
}

\author{
Li Gao ${ }^{1,2}$, Xin Wen ${ }^{3, *}$, Yuntong Guo ${ }^{4}$, Tianming Gao ${ }^{5}$, Yi Wang ${ }^{2}$ and Lei Shen ${ }^{5}$
}

1 School of Economics and Management, China University of Geosciences, Wuhan 430074, China;

E-Mail:gaoli1998@hotmail.com

2 Institute of Policy and Management, Chinese Academy of Sciences, Beijing 100190, China;

E-Mail: wangyi@casipm.ac.cn

3 Centre d'Applications et de Recherches en Télédétection, Université de Sherbrooke, Sherbrooke, QC J1K 2R1, Canada; E-Mail: xin.wen@usherbrooke.ca

4 Department of Earth Science, University of Toronto, Toronto, ON M5S 3B1, Canada;

E-Mail: yuntong.guo@mail.utoronto.ca

5 Institute of Geographic Sciences and Natural Resources Research, Chinese Academy of Sciences, Beijing 100101, China; E-Mails: gaotm10b@igsnrr.ac.cn (T.G.); shenl@igsnrr.ac.cn (L.S.)

* Author to whom correspondence should be addressed; E-Mail: xin.wen@usherbrooke.ca; Tel.: +1-819-571-2381; Fax: +1-819-821-7944.

Received: 23 January 2014; in revised form: 26 March 2014 / Accepted: 3 April 2014 /

Published: 10 April 2014

\begin{abstract}
Carbon sources and sinks as a result of land use and land cover changes (LUCC) are significant for global climate change. This paper aims to identify and analyze the temporal and spatial changes of land use-based carbon emission in the Hubei Province in China. We use a carbon emission coefficient to calculate carbon emissions in different land use patterns in Hubei Province from 1998 to 2009. The results indicate that regional land use is facing tremendous pressure from rapid carbon emission growth. Source:sink ratios and average carbon emission intensity values of urban land are increasing, while slow-growing carbon sinks fail to offset the rapidly expanding carbon sources. Overall, urban land carbon emissions have a strong correlation with the total carbon emissions, and will continue to increase in the future mainly due to the surge of industrialization and urbanization. Furthermore, carbon emission in regions with more developed industrial structures is much higher than in regions with less advanced industrial structures. Lastly,
\end{abstract}


carbon emission per unit of GDP has declined since 2004, indicating that a series of reform measures i.e., economic growth mode transformation and land-use structure optimization, has initiated the process of carbon emission reduction.

Keywords: land use and land cover change; carbon emission; Hubei Province; carbon reduction

\section{Introduction}

Global concentrations of the greenhouse gases (GHG) in the atmosphere, including carbon dioxide $\left(\mathrm{CO}_{2}\right)$, methane $\left(\mathrm{CH}_{4}\right)$, and nitrous oxide $\left(\mathrm{N}_{2} \mathrm{O}\right)$, have increased measurably over the past decades; this increase has given rise to significant risks for climate change. Though the critical factors of increased GHG emissions remain under debate, most scholars agree that the land use and land cover change (LUCC) due to anthropogenic disturbances has altered the atmosphere in ways that have led to a rapid upsurge of GHG emissions [1-5].

LUCC directly affects the exchange of greenhouse gases between terrestrial ecosystems and the atmosphere [6,7]. The dynamics of terrestrial ecosystems rely on interactions between different biogeochemical cycles, such as the carbon cycle, nutrient cycle, and the hydrological cycle, all of which may be modified by LUCC. Carbon is exchanged naturally between these systems and the atmosphere through photosynthesis, respiration, decomposition, natural weathering of rocks, and the combustion of fossil fuels. Therefore, land use changes can alter carbon stocks in these pools, as well as exchanges between them and the atmosphere.

The relationship between LUCC and carbon emissions has garnered critical attention from scientists worldwide. A growing portion of the literature has focused on typical terrestrial ecosystems such as forests, grasslands, rice fields, etc. [8-16], but overall research of various land use patterns needs to be expanded further $[17,18]$. Research on different land use patterns' overall carbon emission effects can be useful for forecasting future carbon emissions and proposing appropriate carbon emission reduction countermeasures. Current research on the impact of land use changes on provincial carbon emission in China is mostly concentrated in Sichuan and Guangdong [19,20].

This study aims to identify and analyze the temporal and spatial changes of land use carbon emission on a regional level. It takes a typical central Chinese province, Hubei, and analyzes the spatiotemporal characteristics of regional land use's carbon emission based on carbon sources or carbon sinks of different land use patterns, from the perspective of land use type and structural changes. This in turn provides a reference for land use structure optimization and low-carbon economic development in Hubei Province.

\section{Study Area and Data Sources}

\subsection{Study Area}

Located at the middle reaches of the Yangtze River, Hubei Province (Figure 1) is the economic center as well as the transport hub of central China. It is about $740 \mathrm{~km}$ from east to west, $470 \mathrm{~km}$ from 
south to north; mountains account for $55.5 \%$ of this area, hills and hillocks comprise $24.5 \%$, and plains and lakes encompass $20 \%$.

Figure 1. The location of Hubei Province in China.

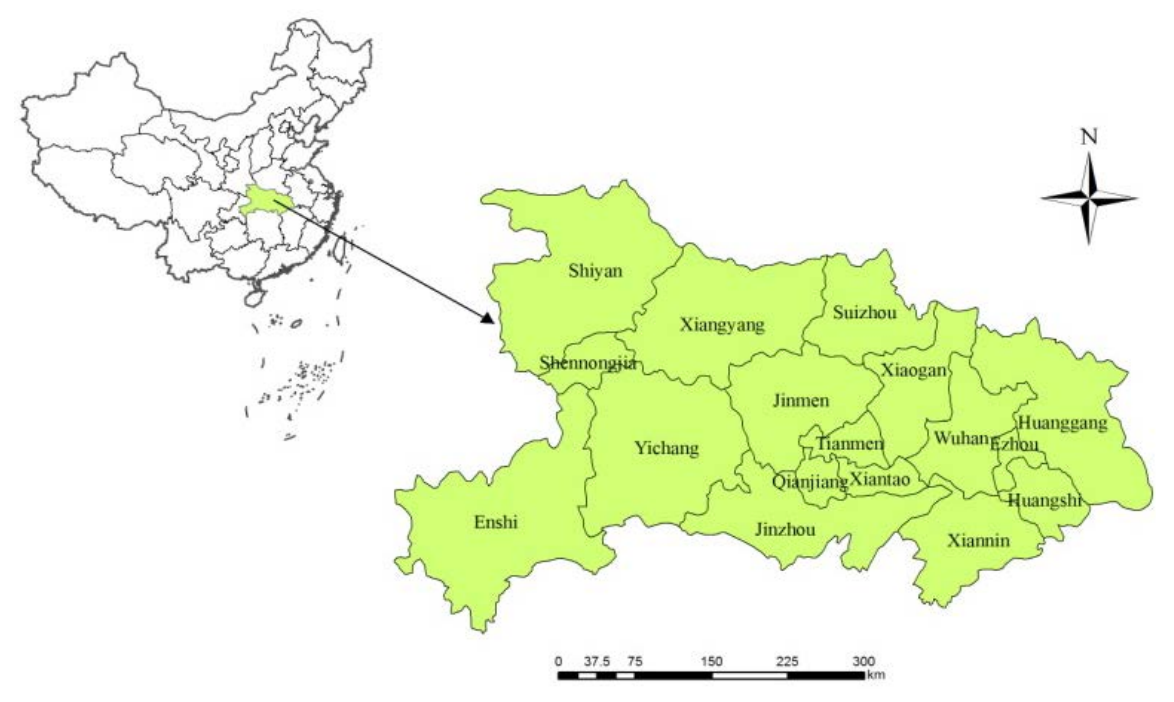

Hubei Province reached a population of 57.79 million in 2012, with a GDP of 2.22 trillion yuan, and a growth rate of $11.3 \%$, 3.5\% faster than the national average, and ranking ninth in the country. The added values of the primary, secondary and tertiary industries were 284.87 billion yuan, 1.11 trillion yuan and 821.09 billion yuan, respectively, with an increase of $4.7 \%, 13.2 \%$ and $10.8 \%$. Hubei Province, as the center of the state's "Rise of Central China” strategy, is a national strategic transportation and shipping hub, which connects the eastern technology-intensive industrial areas and the western resource-rich region.

In recent years, there has been a surge of industrialization and urbanization in Hubei Province. However, during this process of rapid industrialization, Hubei's land ecosystems have been greatly affected by human activities, and land use patterns have changed as a result. It is important to scientifically analyze Hubei's carbon emissions from the perspective of land use change.

According to Hubei Provincial Land Use Planning (2006-2020) and Hubei Annual Land Use Change Survey Data (Hubei Provincial Land and Resources Department, Hubei Provincial Statistics Bureau), by the end of 2010, agricultural land area covered 14,651,800 hectares, which accounted for $78.82 \%$ of the total, among which $4,664,100$ hectares of arable land accounted for $31.83 \%$; 424,500 hectares of grassland accounted for 2.90\%; 7,936,900 hectares of forest accounted for $54.17 \%$. The forest has increased 860,000 hectares in the past decade, and the net increase of forest cover is $13.9 \%$. However, the arable land keeps falling by some 51,200 hectares annually while the population keeps increasing 83,611 annually, thus sharpening the conflicts between population and arable land. Meanwhile the soil erosion and land pollution have become serious and the overall quality of arable land is not high. The urban land measures 1,400,400 hectares, among which residential and industrial land measure 1,008,600 hectares, and transportation land measures 917,000 hectares. The unused land was 2,536,700 hectares (Figure 2) (use of the second land survey data about current land use has not yet been authorized, so the updated land use change survey result is from 2008). 
Figure 2. The proportion of land use patterns in Hubei Province in 2008.

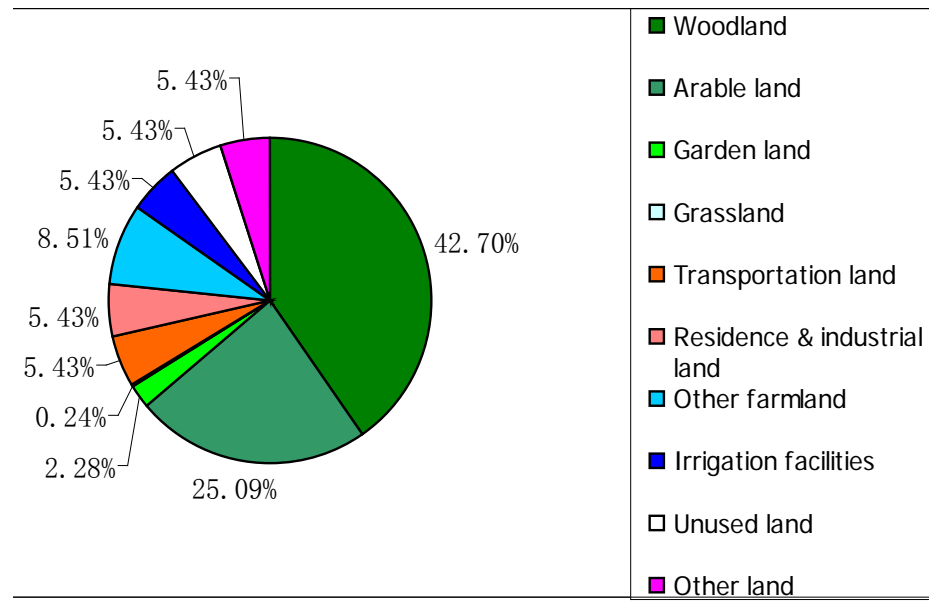

\subsection{Data Sources}

The data used in this study primarily comes from China Statistical Yearbook, Chinese Yearbook of China, China Land Yearbook, China Land and Resources Yearbook, China Energy Statistical Yearbook from 1999 to 2011, the sixth and the seventh national forest resources inventory data, Hubei Rural Statistical Yearbook, Hubei Land Uses Overall planning (2006-2020), and annual statistical data from cities, regions, and counties of Hubei. Land cover information, such as annual change in forest, grassland, farmland, and urban land were obtained from the Second National Overall Planning of Land Use. The data used in the carbon emission forecast was collected from the Twelfth Five Year Plan of Hubei province (2011-2015) and National Carbon Reduction Scheme.

\section{Methods}

In previous research, a number of methods for detection and monitoring of LUCC changes have been reviewed, including land use and land cover change investigation, remote sensing and geographic information system (GIS) techniques [21-24]. Scholars have mainly focused on several typical kinds of land use patterns, such as forests, grasslands, crops, etc. and calculated their biomass when estimating a terrestrial ecosystem's carbon emission [25]. In this paper, land use planning data of the study area is used to evaluate the carbon emission effect of different land use patterns. Land use patterns of the study area were selected according to regional land use planning classification. In the study of carbon sinks' effects of different land use patterns, land use patterns are classified into four categories: forests (includes gardens), grasslands, arable land and urban land. Forest carbon emissions recalculated based on Fang's weighted average coefficient of China's forest carbon emissions [24]. Arable land is both a carbon sink and a carbon source; therefore the carbon emission is the summation of carbon emission and sequestration, and is calculated with a carbon conversion factor. Ditches, yards, water aquaculture and other minimal carbon emission agricultural land types are not included in this paper. Due to the complex and diverse types of urban land, carbon emissions of urban land cannot be reflected simply through the construction area but primarily through the conversion of energy consumption carbon data. Unused land has not been analyzed due to its negligible contribution to carbon emissions in the study area. 


\subsection{Forests}

Currently, national or regional scale forest biomass is calculated based on forest resources inventory data, which means that the conversion between biomass and volume of timber (Biomass Expansion Factor, $B E F$ ) should be established first. Research shows that $B E F$ values change in relation to forest age, site, stand density and stand conditions, while stand volume comprehensively reflects the changes in these factors, therefore, stand volume can be used as a variable to reflect changes in BEF. Based on this “conversion factor continuous function method”, established by Fang and others [24], namely:

$$
\begin{gathered}
B E F=a+\frac{b}{x} \\
Y=\sum_{i=l}^{m} \sum_{j=1}^{n} \sum_{l=1}^{k} A_{i j l} \cdot B E F_{i j l} \cdot x_{i j l} \text { (plot scale) } \\
Y=a \sum_{i=l}^{n} A_{i} x_{i}+b A(\text { regional or provincial scale) } \\
Y=A \cdot x \cdot B E F \text { (national scale) }
\end{gathered}
$$

in these equations, $a$ and $b$ are constants.

In Equation (1), when the stock volume is large (indicative of a mature forest), $B E F$ tends have to constant value $A$; when stock volume is small (young forest), $B E F$ is very large. This simple mathematical relationship coincides with the allometry theory and can be applied to almost all forest types. This formula provides a quick and effective way for scaling plot investigation to region estimation of forest biomass calculation. In Equations (2) and (3), $Y, A, x$ and $B E F$ are the corresponding conversion factors of national total biomass, total area and national average stock volume respectively; $A_{i}, V_{i}, x_{i}$ and $B E F_{i}$ are corresponding conversion factors of provincial total area, total stock volume, and average stock volume respectively of certain forest type in the province $i ; i, j$ and $l$ are province, status level, and age class respectively; $A_{i j l}, X_{i j l}$ and $B E F_{i j l}$ are area, average stock volume, and conversion factor of the province $i$, status level $j$, and age class $l$ respectively; $m, n$ and $k$ are province status level and age class respectively. Its derivation can be seen in Fang et al. [25,26].

\subsection{Grassland}

Normalized difference vegetation index (NDVI) provides effective information for large-scale vegetation dynamics and spatial distribution research. It is often used as an index for vegetation biomass and productivity since it has a positive correlation with them [27]. Fang [24] and others calculated China's grassland biomass and spatial distribution variation through the relationship between NDVI and land biomass. The NDVI applied was from GIMMS 1982-1999 with 8 km resolution and data collected every 15 days. This data has been used globally as well as in China's vegetation productivity study; the data correction and processing can be seen in Piao, et al. and Zhou et al. [28,29].

In order to establish relationship between NDVI and land biomass, the maximum NDVI of every study space in each year was calculated first, indicated as $N D V I_{\max }$. The average $N D V I_{\max }$ was then calculated for corresponding grasslands of each province during 1982-1999. Finally, regression model (5) was 
established with $N D V I_{\max }$ as the independent variable and biomass density as the dependent variable. With model (5) and $N D V I_{\max }$ in 1982-1999, China's ground biomass and its temporal and spatial variation in 1982-1999 could be calculated, and detailed data processing is described in Piao et al. [30]:

$$
Y=179.71 \times N D V I_{\max }^{1.6228}\left(R^{2}=0.71, p<0.0001\right)
$$

In grassland ecosystems, underground biomass accounted for a large proportion of the total biomass. The underground biomass:ground biomass ratios are used in the estimation of underground and total biomass.

\subsection{Urban Land}

Urban land is comprised of complex and diverse land uses, such as commercial services, public facilities, public buildings, mining warehouses, transportation, water conservancy facilities and some specially used land. Given this complexity, calculating the carbon emission coefficient for such a system is not feasible with the traditional methods used in terrestrial ecosystem carbon emission/sequestration studies. Consequently, in this paper, we considered three main sources of carbon emissions in urban areas: transportation, residential heating (natural gas and fuel oil) and industrial carbon emission. Car usage and home heating involved a relatively simple translation from energy use to carbon dioxide emissions, and industrial carbon emission mainly resulted from energy consumption. Thus, we use $\mathrm{C}$ sequestration coefficient of coal consumption, $\mathrm{C}$ sequestration coefficient of oil consumption and $\mathrm{C}$ sequestration coefficient of gas consumption to estimate urban land carbon emission, which is one of the most widely applied methods in analyzing carbon emission. The equation can be expressed as follows:

$$
E_{t}=\delta f \cdot E f+\delta m \cdot E m+\delta n \cdot E n
$$

In the formula, $E_{t}$ is carbon emission; $E f$ is a standard amount of coal used for charcoal consumption; $\delta f$ is the carbon emission conversion coefficient of coal consumption; $E m$ is the standard amount of coal for oil consumption; $\delta m$ is the carbon emission conversion coefficient of oil consumption; $\mathrm{E}_{\mathrm{n}}$ is standard coal amount used for gas consumption; $\delta m$ is the carbon emission conversion coefficient of gas consumption. Here, a carbon emission decomposition model algorithm proposed and improved by Xu et al. [31] is used. The decomposition model of carbon emissions per capita is set up by adopting Logarithmic mean Divisia index (LMDI) method based on the base equation of carbon emissions, which is to analyze the influence of energy structure, energy efficiency and economic development to carbon emissions per capita, it reveals the reason for the increase of the carbon emissions per capita [31]. Detailed emission coefficients of different energy consumption are as described in Table 1. 
Table 1. Different carbon emission and sequestration coefficients.

\begin{tabular}{|c|c|c|c|c|}
\hline Category & $\begin{array}{l}\text { Parameter } \\
\text { values }\end{array}$ & $\begin{array}{l}\text { Average } \\
\text { values }\end{array}$ & Unit & Data sources \\
\hline $\begin{array}{l}\text { C sequestration coefficient } \\
\text { of forest }\end{array}$ & -5.77 & - & $\mathrm{Kg}(\mathrm{C}) \mathrm{m}^{2}(\mathrm{a})$ & Fang et al. [24] \\
\hline $\begin{array}{l}\text { C sequestration coefficient } \\
\text { of grassland }\end{array}$ & -0.00221 & - & $\mathrm{Kg}(\mathrm{C}) \mathrm{m}^{2}(\mathrm{a})$ & Fang et al. [24] \\
\hline \multirow{4}{*}{$\begin{array}{l}\text { C sequestration coefficient } \\
\text { of coal consumption }\end{array}$} & 0.756 & \multirow{4}{*}{0.7239} & \multirow{4}{*}{$\mathrm{t}(\mathrm{C}) / \mathrm{t}$} & $\begin{array}{l}\text { Energy Economics Research } \\
\text { Institute of Japan }\end{array}$ \\
\hline & 0.726 & & & $\begin{array}{l}\text { Climate Change Project of China } \\
\text { National Science and Technology } \\
\text { Commission }\end{array}$ \\
\hline & 0.7476 & & & Xu et al. [31] \\
\hline & 0.702 & & & DOE/EIA \\
\hline \multirow{4}{*}{$\begin{array}{l}\text { C sequestration coefficient } \\
\text { of oil consumption }\end{array}$} & 0.586 & \multirow{4}{*}{0.5574} & \multirow{4}{*}{$\mathrm{t}(\mathrm{C}) / \mathrm{t}$} & $\begin{array}{l}\text { Energy Economics Research } \\
\text { Institute of Japan }\end{array}$ \\
\hline & 0.583 & & & $\begin{array}{l}\text { Climate Change Project of China } \\
\text { National Science and Technology } \\
\text { Commission }\end{array}$ \\
\hline & 0.5825 & & & $\mathrm{Xu}$ et al. [31] \\
\hline & 0.478 & & & DOE/EIA \\
\hline \multirow{4}{*}{$\begin{array}{l}\text { C sequestration coefficient } \\
\text { of gas consumption }\end{array}$} & 0.449 & \multirow{4}{*}{0.4226} & \multirow{4}{*}{$\mathrm{t}(\mathrm{C}) / \mathrm{t}$} & $\begin{array}{l}\text { Energy Economics Research } \\
\text { Institute of Japan }\end{array}$ \\
\hline & 0.409 & & & $\begin{array}{l}\text { Climate change project of China } \\
\text { National Science and Technology } \\
\text { Commission }\end{array}$ \\
\hline & 0.4435 & & & Xu et al. [31] \\
\hline & 0.389 & & & DOE/EIA \\
\hline
\end{tabular}

\subsection{Arable Land}

Arable land, as an important element of an agricultural ecosystem, is a major source of greenhouse gas emission. Crop and soil respiration, use of agricultural machinery, irrigation, and fertilizer application all release carbon; however, crop growth also acts as a carbon sink. Thus, the operation of farmland ecosystems is composed of carbon input and output processes.

\subsubsection{Arable Land Carbon Emission}

Carbon emissions of arable land mainly come from chemical fertilizers, agricultural machinery use, and irrigation processes; combined with the carbon conversion coefficient, the formula for arable land carbon emissions is shown in Equation (7) below:

$$
E_{g}=E_{f}+E_{m}+E_{i} \ldots \ldots
$$

In the formula, $E_{g}$ is arable land carbon emissions $(\mathrm{t}) ; E_{f}$ is carbon emissions of chemical fertilizers (t); $E_{m}$ is carbon emissions of agricultural machinery production and applies $(\mathrm{t}) ; E_{i}$ is carbon emissions of 
irrigation (t). The calculations of $E_{f}, E_{m}$, and $E_{i}$ are shown in Equations (8)-(10), and $A, B, C, D$ are conversion coefficients:

$$
E_{f}=G_{f} \times A
$$

$G_{f}$ is the volume of pure chemical fertilizer (t); $A=857.54 \mathrm{~kg} / \mathrm{mg}$ :

$$
E_{m}=\left(A_{m} \times B\right)+\left(W_{m} \times C\right)
$$

$A_{m}$ is arable acreage $\left(\mathrm{hm}^{2}\right) ; W_{m}$ is agricultural machinery dynamics $(\mathrm{kw}) ; B=16.74 \mathrm{~kg} / \mathrm{hm}$; $C=0.18 \mathrm{~kg} / \mathrm{kw}$ :

$$
E_{i}=A_{i} \times D
$$

$A_{i}=$ irrigation acreage $\left(\mathrm{hm}^{2}\right) ; D=266.48 \mathrm{~kg} / \mathrm{hm}^{2}$.

\subsubsection{Arable Land Carbon Sequestration}

Arable land carbon sequestration is calculated with arable crop yield data, economic coefficient and carbon sequestration rate, outlined in Formula (11). According to the current national standard of land use classification GB/T21010-2007, combined with the actual land use in the Hubei Province, the major planted crops include wheat, corn, paddy, soybean, cole, peanut and cotton:

$$
C_{t}=\sum_{i} C_{d}
$$

In the formula, $C_{d}=C_{\mathrm{f}} \mathrm{D}_{\mathrm{w}}=\mathrm{C}_{\mathrm{f}} \mathrm{Y}_{\mathrm{w}} / \mathrm{H}_{\mathrm{t}}, i$ refer to crop types. $i, C_{d}$ is carbon sequestration of a particular crop in its entire growth process $(\mathrm{t})$; $C_{f}$ is carbon absorption of synthetic organic crops per dry mass unit; $D_{w}$ is the biomass production of crops (t); $Y_{w}$ is production of crops $(\mathrm{t})$; $H_{t}$ is economic coefficient of crops. The economic coefficient $\left(H_{t}\right)$ and carbon sequestration rate $\left(C_{f}\right)$ of crops are shown in Table 2.

Table 2. Economic factors $\left(H_{t}\right)$ and carbon sequestration rate $\left(C_{t}\right)$ of main crops.

\begin{tabular}{cccccccc}
\hline Type of corps & Wheat & Corn & Paddy & Soybean & Cole & Peanut & Cotton \\
\hline$H_{t}$ & 0.40 & 0.40 & 0.40 & 0.34 & 0.25 & 0.43 & 0.10 \\
$C_{t}$ & 0.4853 & 0.4709 & 0.4500 & 0.4500 & 0.4500 & 0.4500 & 0.4500 \\
\hline
\end{tabular}

This study is primarily based on the carbon emissions of four land use patterns: arable land, forests, grasslands and urban land, among which urban land is a major carbon source, arable land is both a carbon source and carbon sink, and forests and grasslands are only carbon sinks. Due to the difficulties of accurately calculating the carbon sequestration of different crops, the coefficient method is widely used. The carbon emission coefficients vary with time and region for different land use patterns; the coefficients even vary for the same land use classification with respect to time and spatial scales, This paper focuses on temporal and spatial differences of carbon emission effects of different land use types with current experimental research results; it does not consider carbon emission and sequestration coefficients' temporal and spatial differences of the same types of land use in different regions. Carbon emissions of urban land are estimated with the energy consumption carbon emission coefficient, and 
carbon sequestration coefficient of forest and grassland is estimated with previous research data [32]. The formula for carbon emissions is:

$$
E=\sum e_{i}=\sum T_{i} \cdot \delta_{i}
$$

where $E$ is the total carbon emission; $e_{i}$ is the carbon emission of main land use patterns; $T_{i}$ is acreage of different land use patterns; $\delta_{i}$ is carbon emission and sequestration coefficients of different land use patterns [32]. Different carbon emission and sequestration coefficients have been shown in Table 1.

\section{Result and Analyses}

\subsection{Temporal Changes of Land Use Carbon Emissions}

\subsubsection{Temporal Changes of Carbon Emissions Over 1998-2009}

Carbon emissions recorded an overall increase of 83.59\% in Hubei during the period from 1998 to 2009. A moderate increase (29.07\%) occurred during the period from 1998 to 2001, followed by a sharp rise (66.18\%) during 2002-2009 (Figure 3). An interesting phenomenon occurred between 2004 and 2008 in which carbon emissions slowly declined. For the total variation in carbon emissions from 1998 to 2009, urban land contributed 50.02\% (5902 t) of the total increase in carbon emissions, while grasslands, forests and arable land reflected continuous downward trends from 1998 to 2009 (Figure 4). On the other hand, further analysis of total carbon emissions and main land use patterns show a high correlation coefficient of 0.986 between total carbon emissions and urban land area.

Figure 3. Variations of carbon emissions in Hubei Province during 1998-2009 (10,000 t).

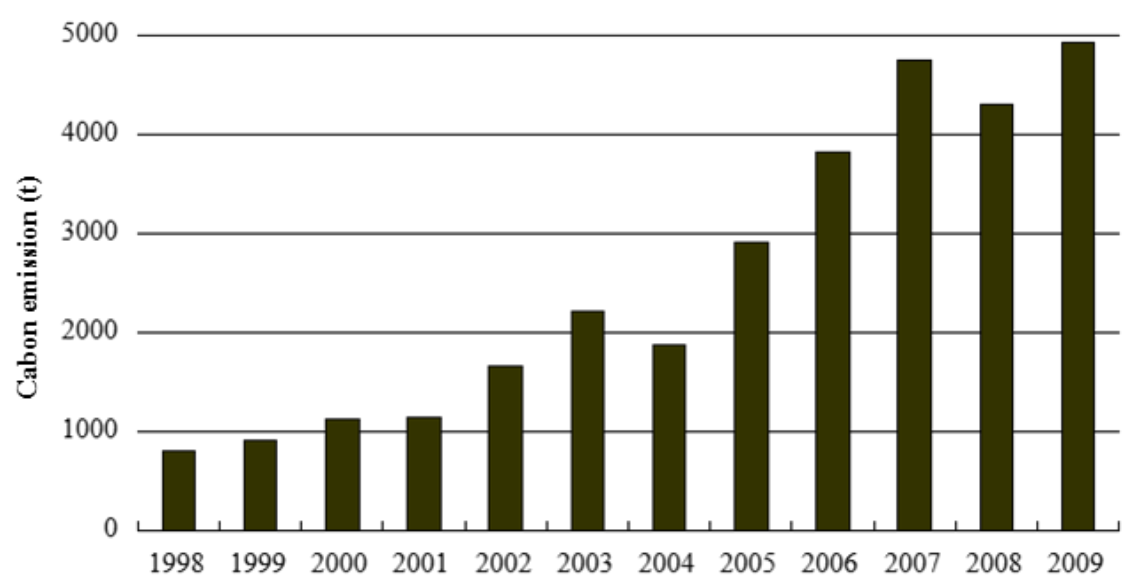

Generally, arable land releases significant amounts of carbon into the atmosphere [33]. Carbon is released largely from microbial decay or burning of plant litter and soil organic matter [34]. In Hubei Province, estimated carbon emissions from arable land were 9665.72 t from 1998 to 2009. Arable land carbon emissions increased by 7.18\% from 1998 to 2009, an average annual emission increase of 1.68 t/year (Figure 5). Meanwhile, farmland irrigation and chemical fertilizers accounted for $69 \%$ and $30 \%$ of total carbon emissions, respectively, and machinery use accounted for only $1 \%$ of the total carbon emissions. Moreover, farmland irrigation is also a main source of carbon emissions in Hubei Province (Figure 6). 
Figure 4. Carbon emissions of main land use patterns in Hubei Province during 1998-2009 (10,000 t).

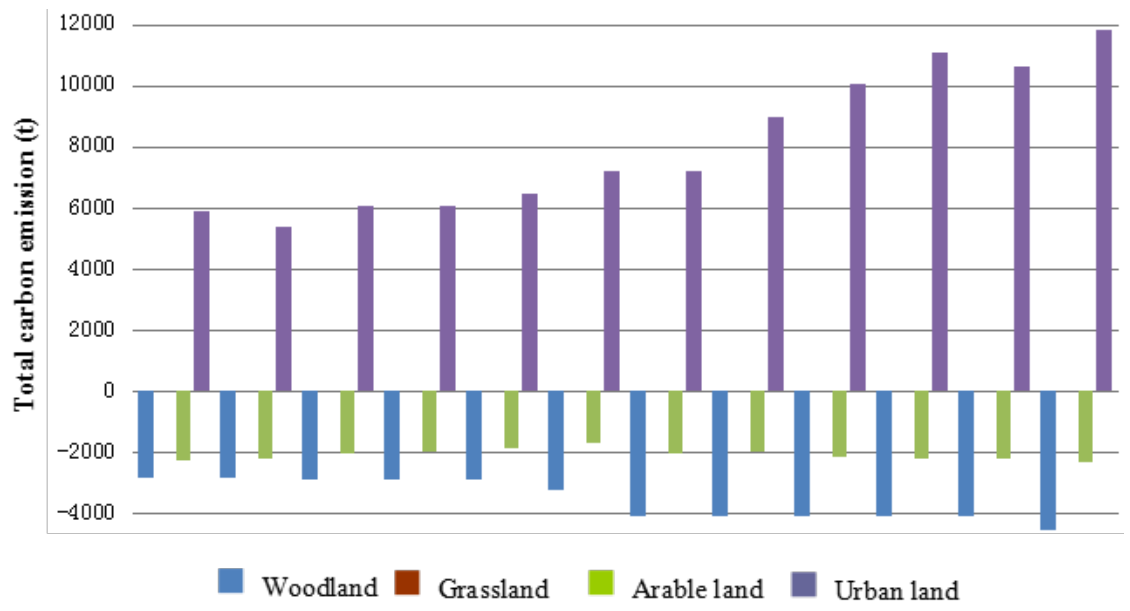

Figure 5. Main carbon sources of arable land in Hubei Province during 1998-2009 (10,000 t).

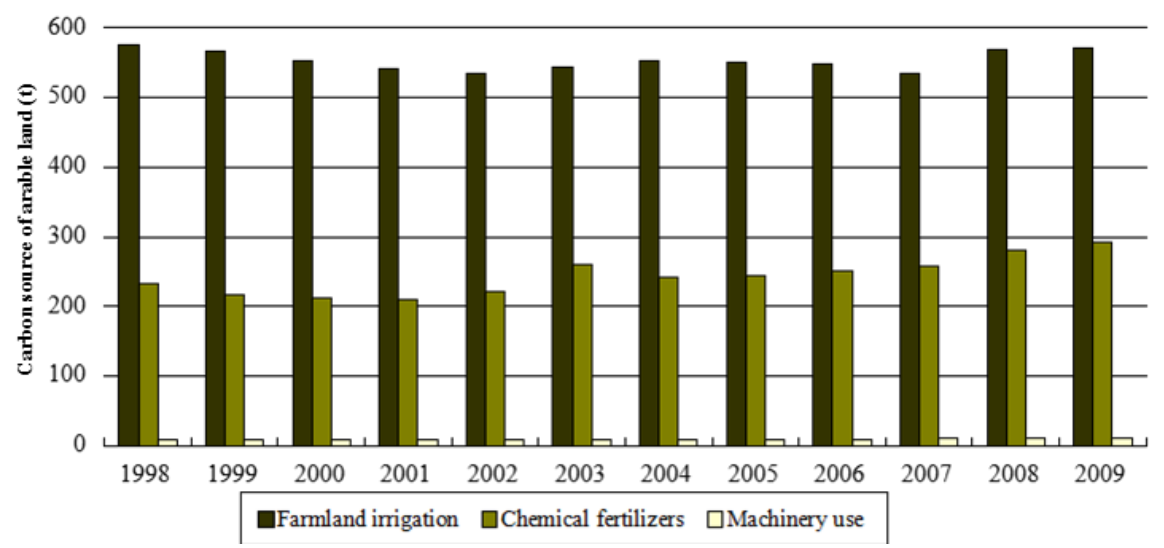

Figure 6. Total carbon emissions of arable land in Hubei Province during 1998-2009 (10,000 t).

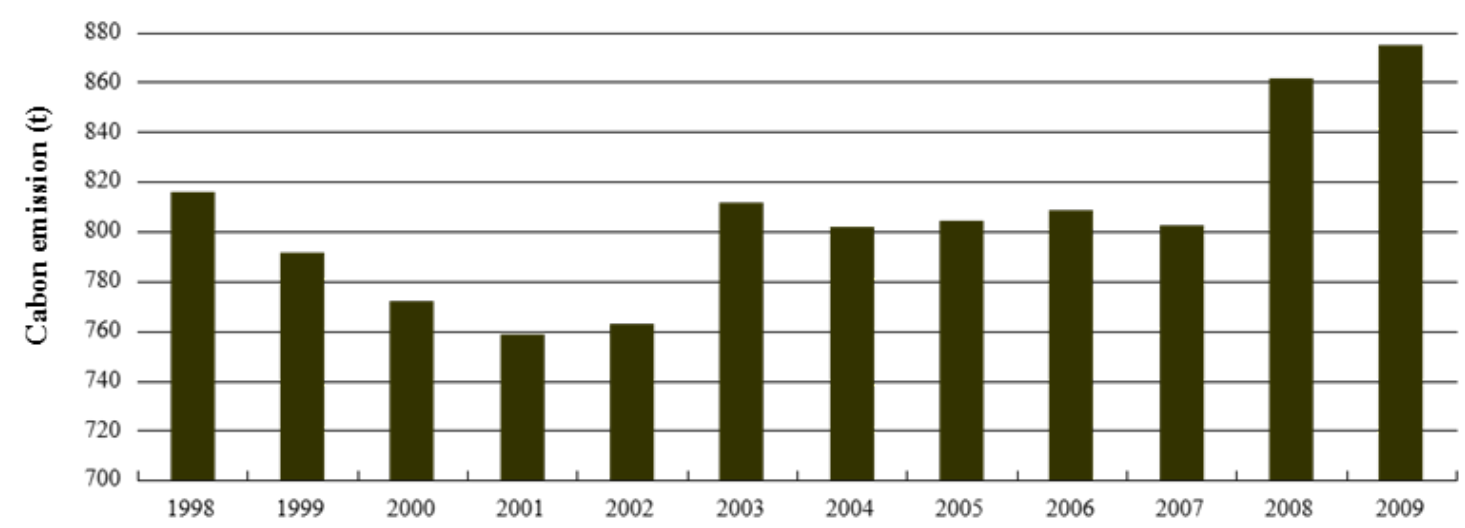

In contrast, Figure 7 shows the total carbon sequestration of arable land in Hubei 1998-2009 and Figure 8 shows the significant crop types that contributed to sequestering carbon emissions in Hubei in 1998-2009. As observed from Figure 7, the estimated amount of carbon sequestration from arable land was 34,841.91 Mt from 1998 to 2009. The total carbon sequestration of arable land in Hubei has an overall increase of $4.48 \%$ during this time. A moderate decrease of $18.09 \%$ was observed from 1998 to 2000, followed by a slight increase of 13.64\% 2004-2009. As shown in Figure 8, paddy remains the primary contribution to carbon emission sequestering 1998-2009, capturing 20,533.89 t during the decade; next 
came wheat, which sequestered 3784.92 t during the same time period, and finally soybean only sequestered $608.12 \mathrm{t}$, while peanut sequestered $713.19 \mathrm{t}$.

Figure 7. Total carbon sequestration of arable land in Hubei Province during 1998-2009 (10,000 t).

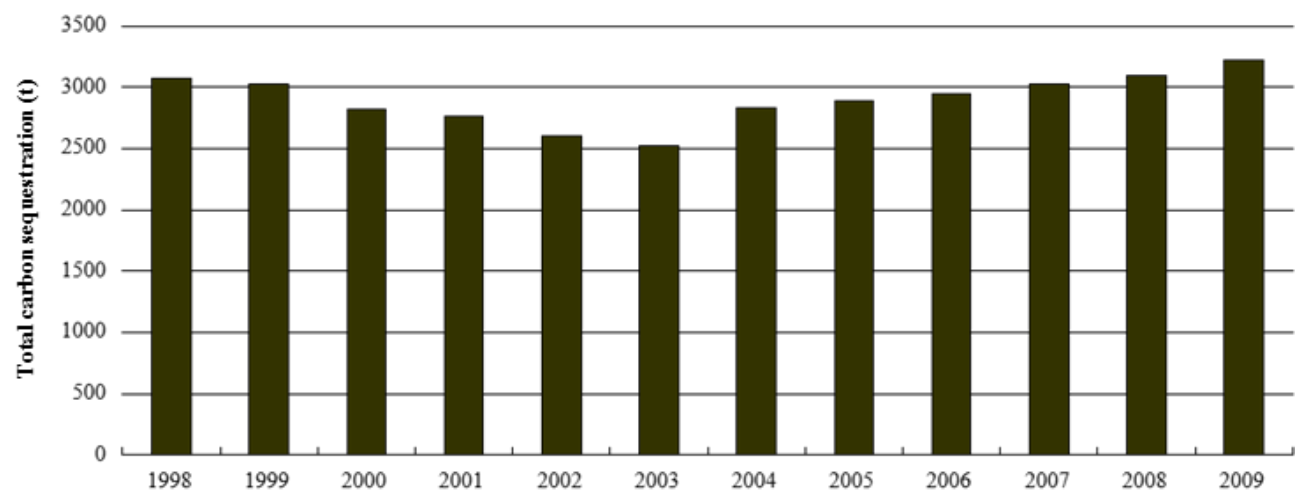

Figure 8. Arable land carbon sequestration of Hubei Province in 1998-2009 (10,000 t).

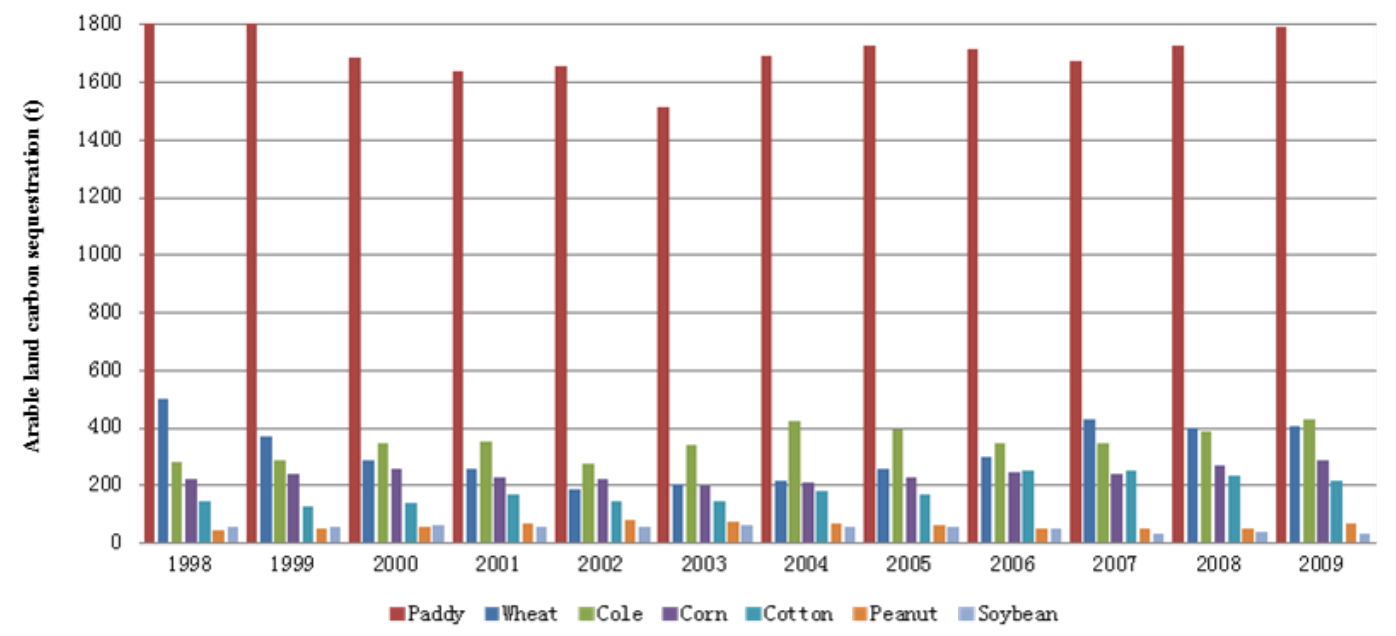

Table 3 shows carbon emission calculation results for the main land use patterns of the Hubei Province in 1998-2009. Carbon sinks and carbon sources are calculated separately for comparison. Table 3 shows that the source:sink ratio has a significant positive correlation with GDP $\left(R^{2}=0.912\right)$. The carbon emissions from urban land and arable land increased on average $5.44 \%$ a year for 12 years, meanwhile carbon sequestration from forests, grasslands and arable land only increased at a slower annual rate of 2.24\%. The source:sink ratios increased from 1.1370 in 1998 to 1.6367 in 2009, reflecting the difficulty of offsetting the increase in carbon emissions. This can be explained by the rapid rise of industrialization and urbanization; energy consumption soared due to an economic growth policy implemented 2000-2010. Meanwhile, Hubei Province's gross domestic product (GDP) experienced a vigorous upward trend with an average annual growth of 11\% after the 1998 financial crisis. The correlation coefficient of source:sink ratio and carbon emission per GDP unit during this time was 0.854 , much higher than 0.01 , which means they were significantly correlated. 
Table 3. Comparison between source:sink ratio and GDP ratio of land use carbon emissions of Hubei Province during 1998-2009.

\begin{tabular}{cccccc}
\hline Year & $\begin{array}{c}\text { Carbon source } \\
(\mathbf{1 0 , 0 0 0} \mathbf{~})\end{array}$ & $\begin{array}{c}\text { Carbon sink } \\
\mathbf{( 1 0 , 0 0 0} \mathbf{~})\end{array}$ & $\begin{array}{c}\text { Source-sink } \\
\text { ratio }\end{array}$ & $\begin{array}{c}\text { GDP } \\
(\mathbf{1 0 0} \text { million yuan) }\end{array}$ & $\begin{array}{c}\text { Carbon emission per GDP } \\
\text { unit (t/100 million yuan) }\end{array}$ \\
\hline 1998 & $6,711.2260$ & $-59,021.7007$ & 1.1370 & $3,704.21$ & $2,182.7199$ \\
1999 & $6,785.0991$ & $-5,877.4141$ & 1.1544 & $3,857.99$ & $2,352.7407$ \\
2000 & $6,820.1378$ & $-5,695.8252$ & 1.1974 & $4,276.32$ & $2,629.1592$ \\
2001 & $6,806.1319$ & $-5,666.1998$ & 1.2012 & $4,662.28$ & $2,445.0100$ \\
2002 & $7,194.1195$ & $-5,527.1136$ & 1.3016 & $4,975.63$ & $3,350.3415$ \\
2003 & $7,985.5226$ & $-5,767.4091$ & 1.3846 & $5,401.71$ & $4,106.3172$ \\
2004 & $8,782.0954$ & $-6,901.7371$ & 1.2724 & $5,633.11$ & $3,337.9932$ \\
2005 & $9,749.4211$ & $-6,970.7315$ & 1.3986 & $6,652.14$ & $4,261.7024$ \\
2006 & $10,857.0198$ & $-7,029.3425$ & 1.5445 & $7,581.32$ & $5,048.8270$ \\
2007 & $11,841.2365$ & $-7,102.0886$ & 1.6673 & $9,230.68$ & $5,134.1265$ \\
2008 & $11,465.7231$ & $-7,171.0512$ & 1.5989 & $11,328.92$ & $3,790.8926$ \\
2009 & $12,672.0564$ & $-7,742.2821$ & 1.6367 & $12,961.10$ & $3,803.5154$ \\
\hline
\end{tabular}

4.1.2. Temporal Changes of Carbon Emission Intensity of Different Land Use Patterns

Current carbon emission intensity studies typically report carbon emissions per GDP unit instead of acreage unit; however, this paper proposes carbon emission indicators based on acreage in the analysis. Given that the majority of current carbon emissions come from urban land, carbon emissions per urban land unit may better reflect the second and third industrial carbon emission differences in the same region, hence this paper utilizes carbon emission per unit urban land acreage as an indicator of total carbon emissions. Due to the continuous growth and expansion of urban land area and energy consumption, the average urban land carbon emission intensity grows rapidly. The carbon emission intensity in 2009 was $85 \%$ higher than in 1998. Detailed carbon emission intensity in 1998-2009 is shown in Table 4, which indicates that rapid economic development and urban land expansion led to rapid growth in energy consumption and rapid growth in carbon emissions after 2002, and the pressure to reduce carbon emissions has increased since then.

Table 4. Average carbon emission intensity of different land use patterns of Hubei Province during 1998-2009 (t/ha).

\begin{tabular}{ccccc}
\hline Year & $\begin{array}{c}\text { Average carbon } \\
\text { emission intensity of } \\
\text { carbon source area }\end{array}$ & $\begin{array}{c}\text { Average carbon } \\
\text { sequestration intensity of } \\
\text { carbon sink area }\end{array}$ & $\begin{array}{c}\text { Average carbon } \\
\text { emission intensity of } \\
\text { urban land }\end{array}$ & $\begin{array}{c}\text { Overall average } \\
\text { carbon emission } \\
\text { intensity }\end{array}$ \\
\hline 1998 & 10.4959 & -5.7276 & 45.3478 & 4.7683 \\
1999 & 10.6804 & -5.7278 & 45.7544 & 4.9526 \\
2000 & 10.8241 & -5.7290 & 45.9890 & 5.0951 \\
2001 & 10.9029 & -5.7299 & 45.8138 & 5.1729 \\
2002 & 11.9247 & -5.7303 & 48.3547 & 6.1944 \\
2003 & 13.4020 & -5.7306 & 53.3615 & 7.6714 \\
2004 & 14.6490 & -5.7332 & 58.8770 & 8.9159 \\
2005 & 16.0948 & -5.7376 & 65.3891 & 10.3572 \\
2006 & 17.8489 & -5.7380 & 72.9231 & 12.1108 \\
2007 & 19.4235 & -5.7380 & 79.4148 & 13.6855 \\
2008 & 18.3568 & -5.7381 & 75.7441 & 12.6488 \\
2009 & 20.2986 & -5.7398 & 83.6699 & 14.5588 \\
\hline
\end{tabular}




\subsection{Spatial Variation of Land Use Carbon Emission}

Using the data in Hubei Provincial Statistical Yearbook 2011, this study selected the date of population, GDP, energy consumption and other indicators of socio-economic statistics of 17 cities, states and counties in 2009 to calculate and analyze carbon emission of different land use patterns, and the results are shown in Table 5.

\subsubsection{Spatial Variation of Carbon Emission}

This study used the parameters and calculations outlined in Table 5 and applied ArcGIS 9.3 to study the spatial differentiation of carbon emission from different land use patterns seen in Figure 9. According to Table 5 and Figure 9, Wuhan is the highest carbon emission region, with 47,954,700 t, much higher than other cities in the province. As the capital of Hubei Province, Wuhan is the most important industrial base with developed secondary industry; urban land accounted for $8 \%$ of its total land area. Wuhan is the most urbanized city in the province, with an average carbon sink area of 3978.99 ha, lower than other regions. In addition to this, Wuhan's urban construction has been developing quickly in recent years, so the need for carbon emission reduction is enormous.

Figure 9. Spatial differentiation of total carbon emissions in Hubei Province.

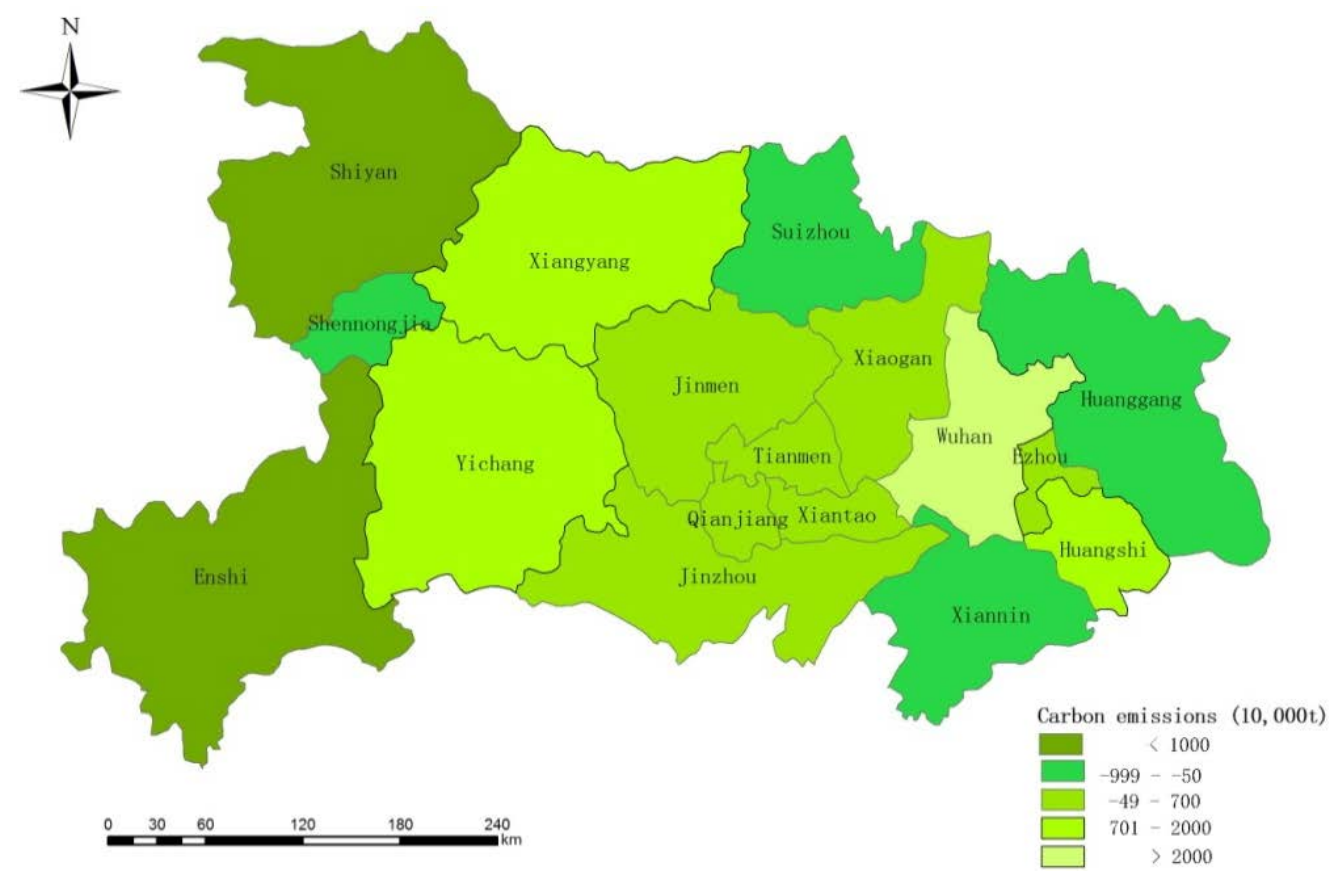

Xiangyang, Yichang and Huangshi are three cities with rapidly developing economies and their carbon per capita are ranked among the top four cities in the province. Jingmen, Xiaogan, Tianmen, Qianjiang, Xiantao and Jingzhou have median carbon emissions ranging $-0.5-20$ million t. Shennongjia, Suizhou, Huanggang and Xiannin are four cities with carbon emission of $-10-0.5$ million t, among which the carbon sink area per capita of Shennongjia is 1738.2 ha due to its sparse population, while the other three cities measure higher than 2500 ha in carbon sink area per capita. Carbon emissions of Shiyan and Enshi are over -10 million $\mathrm{t}$ for their rich forest resources, serving to alleviate the pressure to reduce carbon emissions in the Hubei Province. 


\subsubsection{Spatial Variation of Major Indicators of Carbon Emission}

Source:sink ratios reflect the pressure of reducing carbon emissions in different regions, the higher source:sink ratio the greater pressure on carbon emissions. As shown in Table 5, the source:sink ratio of Hubei Province in 2009 was 2.40. Wuhan has the highest source:sink ratio of 15.58 in the province due to its low forest coverage and large urban area; its carbons sinks cannot offset its carbon emissions, hence Wuhan has huge emission reduction pressure. The source:sink ratios of Huangshi, Xiangyang, Jingmen, Xiantao and Qianjiang range from 2 to 4 . The average of source:sink ratios of the remaining areas is less than 2, among which Shiyan, Enshi, Shennongjia's source:sink ratios are less than 0.5 , due to their larger forest coverage. The spatial differentiation of source:sink ratios and carbon emission per unit output can be seen from Figure 10.

Figure 10. Spatial differentiation of source:sink ratio and per unit of output carbon emission.

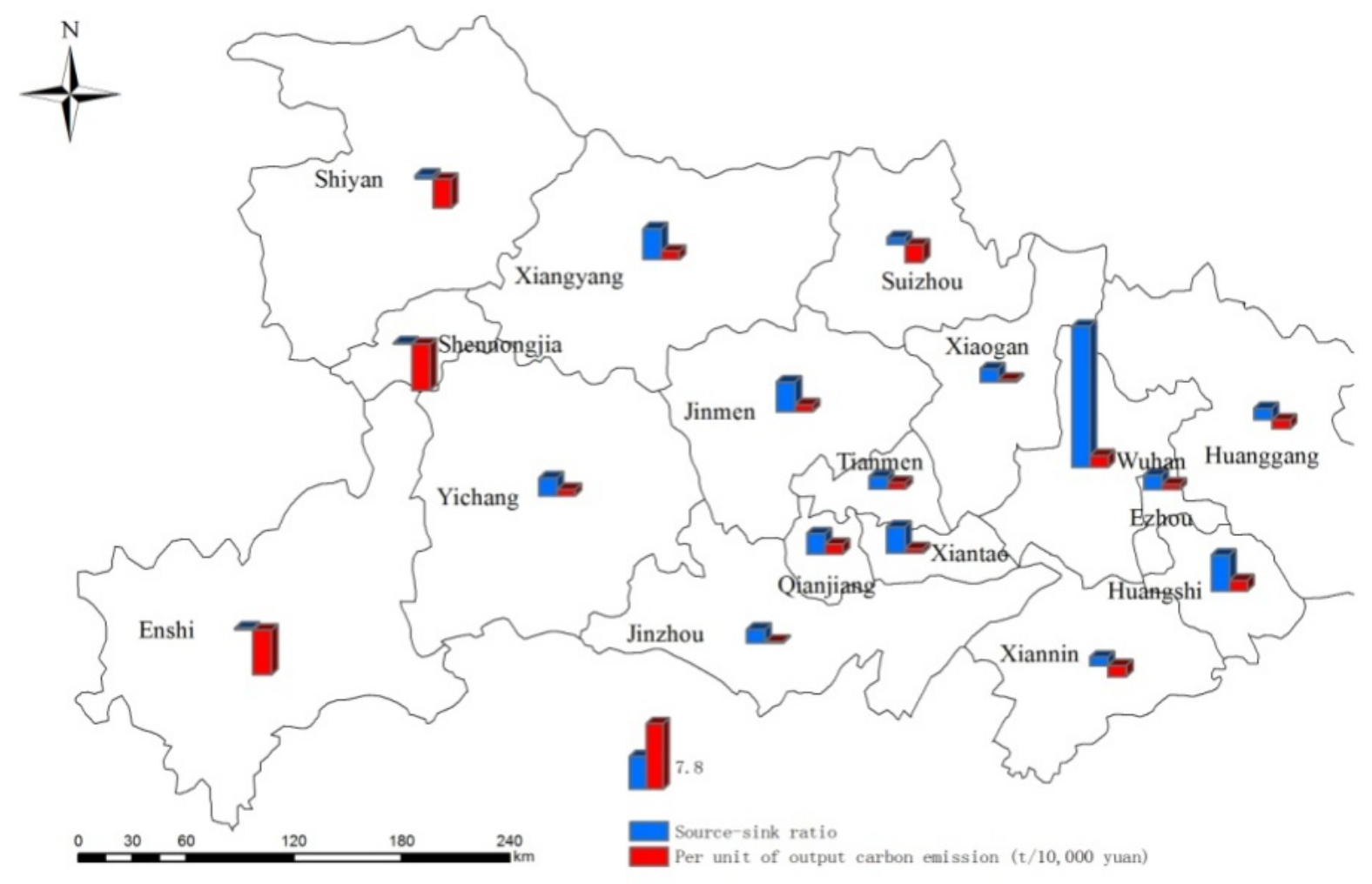

In 2009, carbon emission per unit of output of Wuhan, Huangshi and Qianjiang all surpassed 1t/10,000 yuan, Yichang, Xiangyang, Ezhou, Jingmen, Xiaogan, Jingzhou, Xiantao, and Tianmen is 0.1-1 t/10,000 yuan, the rest is less than $1 \mathrm{t} / 10,000$ yuan, among which Enshi and Shennongjia have about $-5 \mathrm{t} / 10,000$ yuan due to their rich forest resources.

The average construction carbon emission of Hubei Province in 2009 was 330.79 t/ha. From Table 5, the average urban land carbon emissions of Wuhan, Yichang, Ezhou and Shiyan were above $500 \mathrm{t} / \mathrm{ha}$, among which Wuhan is approximately $800 \mathrm{t} / \mathrm{ha}$ for its advanced industrialization. The average construction carbon emissions of Huangshi, Xiaogan, Huanggang, Xianning, Enshi, Xiantao, Qianjiang, and Shennongjia ranged from 200 to $400 \mathrm{t} / \mathrm{ha}$, Xiangyang is $400 \mathrm{t} / \mathrm{ha}$. The average construction carbon emission of Jingmen, Jingzhou, and Suizhou was lower than $200 \mathrm{t} / \mathrm{ha}$, among which Tianme was the lowest one with $61.38 \mathrm{t} / \mathrm{ha}$. 
Table 5. Carbon emission calculation results of cities and states land use in Hubei province in 2009.

\begin{tabular}{|c|c|c|c|c|c|c|c|c|c|}
\hline Region & $\begin{array}{c}\text { GDP } \\
\text { (100 million yuan) }\end{array}$ & $\begin{array}{c}\text { Forest } \\
(\mathbf{1 0 , 0 0 0 ~ t )}\end{array}$ & $\begin{array}{l}\text { Grassland } \\
(10,000 \text { t })\end{array}$ & $\begin{array}{c}\text { Arable land } \\
(\mathbf{1 0 , 0 0 0 ~ t )}\end{array}$ & $\begin{array}{c}\text { Urban land } \\
(\mathbf{1 0 , 0 0 0 ~ t )}\end{array}$ & $\begin{array}{c}\text { Source-sink } \\
\text { ratio }(10,000 \text { t) }\end{array}$ & $\begin{array}{c}\text { Total carbon } \\
\text { emission }(\mathbf{1 0 , 0 0 0} t)\end{array}$ & $\begin{array}{c}\text { Average carbon emission } \\
\text { of urban land (t/ha) }\end{array}$ & $\begin{array}{c}\text { Average carbon } \\
\text { emission (t/ha) }\end{array}$ \\
\hline Wuhan & 4620.18 & -146.73 & -0.002358 & -186.20 & 5128.40 & 15.58 & 4795.47 & 792.15 & 20.05 \\
\hline Huangshi & 571.59 & -284.65 & -0.014123 & -76.18 & 1096.18 & 3.08 & 735.33 & 221.76 & 4.79 \\
\hline Shiyan & 550.96 & -1781.11 & -0.044934 & -123.13 & 898.06 & 0.48 & -1006.22 & 744.05 & -2.01 \\
\hline Yichang & 1272.33 & -889.99 & -0.007703 & -566.18 & 2468.32 & 1.79 & 1012.14 & 504.77 & 1.62 \\
\hline Xiangyang & 1201.01 & -710.85 & 0.022310 & -206.66 & 1885.59 & 2.12 & 968.05 & 401.62 & 2.62 \\
\hline Ezhou & 323.71 & -28.64 & -0.002155 & -553.45 & 663.61 & 1.34 & 81.51 & 544.39 & 0.18 \\
\hline Jinmen & 600.10 & -432.33 & -0.023514 & -46.90 & 941.20 & 2.00 & 461.94 & 195.11 & 3.49 \\
\hline Xiaogan & 672.88 & -220.99 & -0.007127 & -358.28 & 1067.19 & 1.97 & 487.91 & 229.01 & 1.62 \\
\hline Jinzhou & 709.58 & -116.49 & -0.001508 & -302.63 & 752.94 & 1.99 & 333.82 & 115.96 & 1.16 \\
\hline Huanggang & 730.19 & -739.36 & -0.015544 & -444.29 & 964.01 & 0.90 & -219.66 & 211.59 & -0.46 \\
\hline Xiannin & 418.45 & -770.24 & -0.032983 & -131.57 & 613.94 & 0.72 & -287.90 & 247.46 & -0.94 \\
\hline Suizhou & 341.91 & -592.59 & -0.019671 & -179.45 & 295.43 & 0.45 & -476.63 & 139.35 & -1.89 \\
\hline Enshi & 294.26 & -1732.45 & 0.034787 & -139.68 & 319.90 & 0.19 & -1552.25 & 239.45 & -2.70 \\
\hline Xiantao & 242.55 & -11.19 & -0.000592 & -110.60 & 267.05 & 2.45 & 145.26 & 241.02 & 1.54 \\
\hline Qianjiang & 234.01 & -11.03 & -0.000019 & -106.92 & 377.24 & 3.51 & 259.30 & 382.99 & 2.33 \\
\hline Tianmen & 186.86 & -18.75 & -0.000605 & -81.70 & 172.65 & 1.97 & 72.20 & 61.38 & 0.95 \\
\hline Shennongjia & 10.29 & -63.17 & -0.000405 & -1.61 & 14.40 & 0.23 & -50.38 & 351.32 & -2.90 \\
\hline
\end{tabular}




\section{Conclusions}

This paper explored the spatiotemporal characteristics of land use's carbon emission effects from the perspective of land use type and structural changes in Hubei Province, China. We estimated carbon emissions of different land use patterns, analyzed carbon emission effects of major land use patterns over time and differentiated by region, and compared average carbon emission values of different cities, states and counties on a spatial scale, relating regional land use and carbon emissions. The following main conclusions are reached:

(1) In our study, the total carbon emissions of Hubei Province showed an increase, along with source:sink ratio and the average carbon emission intensity of urban land. The growth rate of these carbon sources has slowed down, but slow-growing carbon sinks still cannot offset these fast-growing carbon sources. Therefore, regional land use is facing tremendous pressure to reduce carbon emissions.

(2) Energy consumption is main cause of the carbon emissions, while urban land is the main carbon source. The carbon emission of urban land has a correlation coefficient of 0.986 with the total carbon emissions. Since 1998, with the expansion of construction areas and the surge of industrialization and urbanization, carbon emissions of urban land have been growing rapidly and continue to show an upward trend.

(3) This great disparity is also reflected in the level of carbon emissions in different cities. In Hubei Province, total carbon emissions, source:sink ratios, average carbon emission intensity, and carbon emission intensity of per unit output varied widely due to the structural differences of land use in the different cities, as well as the varying degrees of economic development, industrial structure and energy structure.

(4) With the slowing of the economy in 2004, carbon emission per unit of GDP declined, indicating that a series of reform measures such as energy structure adjustment and economic growth mode transformation, as well as land-use structure optimization, have achieved some preliminary results in carbon emission reduction.

This paper provided new perspectives and opportunities to analyze land use and carbon emissions on a regional level, and the analytical approach used in this paper gives interesting results which can help policymakers design and implement policies to promote carbon emission reduction, strengthen supervisory work to promote conservation and intensive land use, and promote a regional recycling economy with a sound scientific and rational planning of land use, to thus achieve the sustainable development of Hubei Province.

\section{Acknowledgments}

This work is supported by the Natural Science Foundation of China (No. 41281240618), Information Center of Ministry of Land and Resources, Philosophy and Social Sciences Major Research Project of Ministry of Education (No. 12JZD034), Central Universities Basic Scientific Research Special Fund (No. 201208905, No. G20122007B). 


\section{Conflicts of Interest}

The authors declare no conflict of interest.

\section{References}

1. Williams, E.J.; Hutchinson, G.L.; Fehsenfeld, F.C. $\mathrm{NO}_{\mathrm{x}}$ and $\mathrm{N}_{2} \mathrm{O}$ emissions from soil. Glob. Biogeochem. Cycles 1992, 6, 351-388.

2. Grosso, S.J.; Mosier, A.R.; Parton, W.J.; Ojima, D.S. DAYCENT model analysis of past and contemporary soil $\mathrm{N}_{2} \mathrm{O}$ and net greenhouse gas flux for major crops in the USA. Soil Tillage Res. 2005, 83, 9-24.

3. Brown, D.G.; Robinson, D.T.; Nancy, H.F.F.; Bradley C.R. Land Use and the Carbon Cycle: Advances in Integrated Science, Management, and Policy; Cambridge University Press: Cambridge, UK, 2013; pp. 52-76.

4. Stone, D.; Auffhammer, M.; Carey, M.; Hansen, G.; Huggel, C.; Cramer, W.; Lobell, D.; Molau, U.; Solow, A.; Tibig, L.; Yohe, G. The challenge to detect and attribute effects of climate change on human and natural systems. Clim. Chang. 2013, 12, 381-395.

5. Seto, K.C.; Shepherd, J.M. Global urban land-use trends and climate impacts. Curr. Opin. Environ. Sustain. 2009, 1, 89-95.

6. Dixon, R.K.; Solomon, A.M.; Brown, S.; Houghton, R.A.; Trexier, M.C.; Wisniewski, J. Carbon pools and flux of global forest ecosystems. Science 1994, 263, 185-190.

7. Chase, T.N.; Pielke, R.A.; TKittel, G.F.; Nemani, R.R.; Running, S.W. Simulated impacts of historical land cover changes on global climate in northern winter. Clim. Dyn. 1999, 16, 93-105.

8. Deng, X.Z.; Huang, J.K.; Lin, T.Z.; Shi, Q.L. Interactions between climate, socioeconomics, and land dynamics in Qinghai Province, China: A LUCD model-based numerical experiment. Adv. Meteorol. 2013, 2013, doi:10.1155/2013/297926.

9. Wehr, R.; Mungerb, J.W.; Nelsonc, D.D.; McManusc, J.B.; Zahniserc, M.S.; Wofsyb, S.C.; Saleskaa, S.R. Long-term eddy covariance measurements of the isotopic composition of the ecosystem-atmosphere exchange of $\mathrm{CO}_{2}$ in a temperate forest. Agric. For. Meteorol. 2013, 181, 69-84.

10. Calanca, P.; Vuichard, N.; Campbell, C.N.; Viovyd, C.A.; Fuhrer, J.; Soussana, J.F. Simulating the fluxes of $\mathrm{CO}_{2}$ and $\mathrm{N}_{2} \mathrm{O}$ in European grasslands with the Pasture Simulation Model (PaSim). Agric. Ecosyst. Environ. 2007, 121, 164-174.

11. Vermont, B.; De Cara, S. How costly is mitigation of non- $\mathrm{CO}_{2}$ greenhouse gas emissions from agriculture? A meta-analysis. Ecol. Econ. 2010, 69, 1373-1386.

12. Hu, H.F.; Wang, G.G. Changes in forest biomass carbon storage in the South Carolina Piedmont between 1936 and 2005. For. Ecol. Manag. 2005, 255, 1400-1408.

13. Acharya, B.S.; Rasmussen, J.; Eriksen, J. Grassland carbon sequestration and emissions following cultivation in a mixed crop rotation. Agric. Ecosyst. Environ. 2012, 153, 33-39.

14. Jackson, R.B.; Banner, J.L.; Jobbagy, E.G.; Pockman, W.T.; Wall, D.H. Ecosystem carbon loss with woody plant invasion of grasslands. Nature 2002, 418, 623-626. 
15. Guo, L.P.; Erda, L. Carbon sink in cropland soils and the emission of greenhouse gases from paddy soils: A review of work in China. Chemosphere-Glob. Chang. Sci. 2001, 3, 413-418.

16. Deng, X.Z.; Jiang, Q.O.; Lin, Y.Z.; Han, J.Z. Simulation of the changes of soil organic carbon stock of cropland in China. Geogr. Res. 2010, 29, 93-101. (In Chinese)

17. Miko, U.F.; Surinder, K.S.; Kevin, R.T.; Kailash, P.T.; Donna, L.G. Quantifying the climate-change consequences of shifting land use between forest and agriculture. Sci. Total Environ. 2013, 465, 314-324.

18. Liu, J.Y.; Deng, X.Z. Progress of the research methodologies on the temporal and spatial process of LUCC. Chin. Sci. Bull. 2010, 55, 1354-1362.

19. Deng, X.Z.; Han, J.Z.; Yin, F. Net energy, $\mathrm{CO}_{2}$ emission and land-based cost-benefit analyses of Jatropha Biodiesel: A case study of the Panzhihua region of Sichuan province in China. Energies 2012, 5, 2150-2164.

20. Seto, K.C.; Fragkias, M. Quantifying spatiotemporal patterns of urban land-use change in four cities of China with time series landscape metrics. Landsc. Ecol. 2005, 20, 871-888.

21. Srivastava, P.K.; Han, D.W.; Rico-Ramirez, M.A.; Bray, M.; Islam, T. Selection of classification techniques for land use/land cover change investigation. Adv. Space Res. 2012, 9, 1250-1265.

22. Srivastava, P.K.; Mukherjee, S.; Gupta, M. Impact of urbanization on land use/land cover change using remote sensing and GIS: A case study. Int. J. Ecol. Econ. Stat. 2010, 18, 106-117.

23. Lu, D.; Mausel, P.; Brondizio, E.; Moran, E. Change detection techniques. Int. J. Remote Sen. 2004, 25, 2365-2407.

24. Fang, J.Y.; Guo, Z.D.; Piao, S.L.; Chen, A.P. Terrestrial vegetation carbon sinks in China, 1981-2000. Sci. China Ser. D: Earth Sci. 2007, 50, 1341-1350.

25. Fang, J.Y.; Chen, A.P.; Peng, C.H.; Zhao, S.Q.; Ci, L.J. Changes in forest biomass carbon storage in China between 1949 and 1998. Science 2001, 292, 2320-2322.

26. Fang, J.Y.; Chen, A.P.; Zhao, S.Q.; Ci, L.J. Estimating biomass carbon of China's forest: Supplementary notes on report published in Science (291: 2320-2322) by Fang. et al. (2001). Acta Phytoecol. Sin. 2002, 26, 243-249. (In Chinese)

27. Paruelo, J.M.; Epstein, H.E.; Lauenroth, W.K.; Burke, I.C. ANPP estimates from NDVI for the Central Grassland region of the United States. Ecology 1997, 78, 953-958.

28. Piao, S.L.; Fang, J.Y.; Zhou, L.M.; Guo, Q.; Henderson, M.; Ji, W.; Li, Y.; Tao, S. Interannual variations of monthly and seasonal normalized difference vegetation index (NDVI) in China from 1982 to 1999. J. Geophys. Res. 2003, 108, doi:10.1029/2002JD002848.

29. Zhou, L.; Tucker, C.J.; Kaufmann, R.K.; Slayback, D.; Shabanov, N.V.; Myneni, R.B. Variations in northern vegetation activity inferred from satellite data of vegetation index during 1981 to 1999. J. Geophys. Res. 2001, 106, 20069-20083.

30. Piao, S.L.; Fang, J.Y.; Zhou, L.M.; Tan, K.; Tao, S. Changes in biomass carbon stocks in China's grasslands between 1982 and 1999. Glob. Biogeochem. Cycles 2007, 21, doi:1029/2005GB002634.

31. Xu, G.Q.; Liu, Z.Y.; Jiang, Z.H. Decomposition model and empirical study of carbon emission for China, 1995-2004. China Popul. Resour. Environ. 2006, 16, 158-161. (In Chinese)

32. Liu, Q. The Carbon Emission Calculation of Land Use of Hubei Province. Master's Thesis, Hubei University, Hubei, China, 2013. (In Chinese) 
33. Cole, C.V.; Duxbury, J.; Freney, J.; Heinemeyer, O.; Minami, K.; Mosier, A.; Paustian, K.; Rosenberg, N.; Sampson, N.; Sauerbeck, D.; et al. Global estimates of potential mitigation of greenhouse gas emissions by agriculture. Nutr. Cycl. Agroecosyst. 1997, 49, 221-228.

34. Intergovernmental Panel on Climate Change (IPCC). Climate Change 2001: The Scientific Basis. Contribution of Working Group I to the Third Assessment Report of the Intergovernmental Panel on Climate Change; Cambridge University Press: Cambridge, UK, 2001; pp. 881.

(C) 2014 by the authors; licensee MDPI, Basel, Switzerland. This article is an open access article distributed under the terms and conditions of the Creative Commons Attribution license (http://creativecommons.org/licenses/by/3.0/). 